\title{
Multifactorial and closed head impact traumatic brain injuries cause distinct tactile hypersensitivity profiles
}

A-S. Wattiez ${ }^{1,3}$, W.C. Castonguay ${ }^{1,3}$, O.J. Gaul ${ }^{1}$, J.S. Waite ${ }^{1}$, C.M. Schmidt ${ }^{1}$, A. Reis ${ }^{1}$, B.J. Rea $^{1,3}$, L.P. Sowers ${ }^{3}$, C.J. Cintrón-Pérez ${ }^{4,5,6,7}$, E. Vázquez-Rosa ${ }^{4,5,6,7}$, A.A. Pieper ${ }^{4,5,6,7,8,9,{ }^{*}}$, A.F. Russo $^{1,2,3^{*}}$

${ }^{1}$ Department of Molecular Physiology and Biophysics, ${ }^{2}$ Department of Neurology, University of lowa, lowa City, IA 52242; ${ }^{3}$ Center for the Prevention and Treatment of Visual Loss, Veterans Administration Health Center, lowa City, IA 52246, ${ }^{4}$ Harrington Discovery Institute, University Hospitals Cleveland Medical Center, Cleveland, OH, USA, ${ }^{5}$ Department of Psychiatry, Case Western Reserve University, Cleveland, OH, USA, ${ }^{6}$ Geriatric Psychiatry, GRECC, Louis Stokes Cleveland VA Medical Center; Cleveland, OH, USA, ${ }^{7}$ Institute for Transformative Molecular Medicine, School of Medicine, Case Western Reserve University, Cleveland, OH, USA, ${ }^{8}$ Weill Cornell Autism Research Program, Weill Cornell Medicine of Cornell University, NY, NY

${ }^{9}$ Department of Neuroscience, Case Western Reserve University, School of Medicine, Cleveland, $\mathrm{OH}, \mathrm{USA}$

* Address correspondence to either:

Dr. Andrew A. Pieper

Harrington Discovery Institute

University Hospitals of Cleveland Medical Center

Department of Psychiatry, Case Western Reserve University 
bioRxiv preprint doi: https://doi.org/10.1101/2020.06.01.127944; this version posted June 2, 2020. The copyright holder for this preprint (which

was not certified by peer review) is the author/funder, who has granted bioRxiv a license to display the preprint in perpetuity. It is made available under aCC-BY-NC-ND 4.0 International license.

Louis Stokes VA Medical Center of Cleveland

Tel 216-368-4273

Email: Andrew.Pieper@HarringtonDiscovery.org

or

Dr. Andrew F. Russo

Department of Molecular Physiology and Biophysics

\section{Newton Rd}

University of lowa

lowa City, IA 52242

Tel: $319-335-7872$

Email: andrew-russo@uiowa.edu 


\section{Abstract}

Chronic complications of traumatic brain injury $(\mathrm{TBI})$ represent one of the greatest financial burdens and sources of suffering in society today. A substantial number of these patients suffer from post-traumatic headache $(\mathrm{PTH})$, which is typically associated with tactile allodynia.

Unfortunately, this phenomenon has been under-studied, in large part due to the lack of wellcharacterized laboratory animal models. We have addressed this gap in the field by characterizing the tactile sensory profile of two non-penetrating models of PTH. We show that multifactorial TBI, consisting of aspects of impact, acceleration/deceleration, and blast wave exposure, produces long term tactile hypersensitivity and central sensitization, phenotypes reminiscent of $\mathrm{PTH}$ in patients, in both cephalic and extracephalic regions. By contrast, closed head injury induces only transient cephalic tactile hypersensitivity, with no extracephalic consequences. Both models show more severe phenotype with repetitive daily injury for three days, compared to either one or three successive injuries in a single day, providing new insight into patterns of injury that may place patients at greater risk of developing PTH. Importantly, even after recovery from transient cephalic tactile hypersensitivity, mice subjected to closed head injury had persistent hypersensitivity to established migraine triggers, including calcitonin gene-related peptide (CGRP) and sodium nitroprusside, a nitric oxide donor. Our results offer new tools for studying PTH, as well as preclinical support for a pathophysiologic role of CGRP in this condition.

\section{Summary}

Two models of post-traumatic headache after traumatic brain injury provide novel laboratory tools and insights in relative risks of injury and therapeutic opportunities. 


\section{Introduction}

Traumatic brain injury (TBI), commonly caused by crashes, falls, contact sports, explosions, or assaults, is a leading cause of chronic morbidity and mortality. Indeed, it is estimated that 69 million people worldwide sustain a TBI every year [14], and in the United States alone there are $\sim 5$ million Americans currently living with TBI-related disability. This translates to an annual cost of $\sim \$ 80$ billion, with TBI as the leading cause of death in adults under 45 years of age [18; 31; 43]. After the initial physical injury, TBI involves a complex secondary response with prolonged immune reactivity [55], neurodegeneration [46], mitochondrial dysfunction [24], and cerebrovascular compromise [1]. An estimated $70-90 \%$ of TBls are mild $[6 ; 10 ; 53]$, defined as suffering from momentary changes in consciousness and scoring between 13 and 15 on the Glasgow Coma Scale [48]. While most patients suffering from mild TBI experience resolution of acute symptoms within 12 weeks, subsequent chronic pathological changes in the brain frequently cause long-term disability $[4 ; 10]$. Furthermore, the epidemiologic risk of new TBI is two to five times greater after sustaining a first one [5], such as with repetitive direct impact in athletes or repeated blast exposure in military personnel. Repetitive TBI often leads to severe sensorimotor disability [34], including post-traumatic headache (PTH) associated with severe tactile allodynia [3; 38].

The International Classification of Headache Disorders (ICHD) defines PTH as a secondary headache occurring within 7 days of TBI, or occurring upon regaining of consciousness after trauma [23]. PTH can be acute (resolved within 3 months of onset) or persistent [3], and also shares clinical characteristics of migraine [27; 28]. Despite its high prevalence, however, the pathophysiology of PTH is still poorly understood [3], due in large part to challenges in modeling this condition in animals. Here, we have addressed this gap in the field by characterizing the long-term effects of both single and repeated TBI in mice on a symptom consistent with PTH in people: tactile hypersensitivity in both cephalic and extracephalic regions [29; 33]. 
Specifically, we compared single and multiple TBIs in: (a) closed head impact to mimic a common form of simple TBI, and (b) multifactorial TBI incorporating concussive impact, acceleration/deceleration, and blast wave exposure to mimic more complex TBI. We asked whether mice after closed head impact were sensitized to pain triggers by using a normally nonnoxious dose of two migraine triggers: calcitonin gene-related peptide (CGRP) and the nitric oxide donor sodium nitroprusside (SNP). CGRP and nitric oxide are well-established triggers of migraine in people, and of migraine-like symptoms in rodents [19; 20; 32; 42]. We were particularly interested in whether CGRP might be involved in our mouse models of PTH, given the similarities between PTH and migraine and the recently established efficacy of CGRP-based drugs for migraine prophylaxis and treatment.

\section{Methods}

\section{Animals}

Wildtype outbred CD1 mice were obtained from Charles River Laboratories, Roanoke, IL at 8 weeks of age and acclimated for one week in the animal facility prior to experimental testing. Equal numbers of male and female mice were used. Mice were housed 4 per cage on a 12-h light cycle with food and water ad libitum. All experiments were performed between 8 AM and 3 PM, with mice randomized and investigators blinded to injury status and/or drug treatment. Animal procedures were approved by the University of lowa Animal Care and Use Committee and performed in accordance with standards set by the National Institutes of Health, policies of the International Association for the Study of Pain and ARRIVE guidelines.

Drug administration 
All injections were performed intraperitoneally (i.p.) with a $0.3 \mathrm{~mm} \times 13 \mathrm{~mm}$ needle. Dulbecco

PBS (Hyclone) was used as the diluent and vehicle. The amounts injected were as follows: 0.01 or $0.1 \mathrm{mg} / \mathrm{kg}$ rat $\alpha$-CGRP (Sigma-Aldrich, St Louis, $\mathrm{MO}$ ), 0.25 or $2.5 \mathrm{mg} / \mathrm{kg}$ sodium nitroprusside (SNP) (Sigma-Aldrich, St Louis, MO). Animals were gently handled so that no anesthetic agents were needed during injections. All injections were performed by either WCC, BJR, or ASW. For induction of injuries, anesthetics were used: inhaled 5\% isoflurane for closed head impact or an i.p. injection of $87.5 \mathrm{mg} / \mathrm{kg}$ ketamine, $12.5 \mathrm{mg} / \mathrm{kg}$ xylazine for overpressure injury.

\section{Multifactorial brain injury}

Mice were anesthetized with ketamine $(87.5 \mathrm{mg} / \mathrm{kg})$ and xylazine $(12.5 \mathrm{mg} / \mathrm{kg})$ via i.p. injection, and then placed in an enclosed chamber constructed from an air tank partitioned into two sides and separated by a port covered by a mylar membrane. The pressure in the side not containing the mouse was increased to cause membrane rupture, which generated a 1-2 ms jet airflow blast wave that reached the animal's head at an average of 25 pounds per square inch. The head remained untethered in a padded holder, while the body was fully shielded by a metal tube. The blast pressure wave produced upon membrane rupture provides a concussive injury, which is followed by acceleration/deceleration of the head and then exposure to the ensuing air wave within an enclosed space. This procedure is routinely performed in our laboratory [17; 51 ; $57 ; 58]$. Immediately after injury, the mouse was removed from the restraint and placed in its home cage to recover from the anesthetic. Sham mice underwent the same anesthesia, handling and exposure to the noise coming for the rupture of the mylar membrane, but were not placed within the TBI apparatus and therefore not exposed to injury. Mice were monitored until they were fully recovered from anesthesia and able to perform the righting reflex.

\section{Closed head impact TBI}


A previously described model of weight drop-mediated TBI was used [26]. Mice were anaesthetized with $5 \%$ isoflurane for $\sim 2$ min, then immediately placed on a foam cushion in a head trauma device. The instrument consists of a fiberglass tube $(80 \mathrm{~cm}$ high, inner diameter 13 $\mathrm{mm}$ ), placed vertically over and lightly touching the head. A $30 \mathrm{~g}$ metal weight was then dropped from the top of the tube to strike the head at the temporal right side between the corner of the eye and the ear. The foam cushion prevented rotation of the head. Immediately after impact, mice were placed in their home cage and observed until their righting reflex returned. Shamtreated animals were anaesthetized but not subjected to the weight drop.

There were no visible physical signs of trauma in any of the animals exposed to either form of $\mathrm{TBI}$, and all animals recovered similarly to sham mice. In each injury group, 2 animals (1 male and 1 female) were euthanized 5 min after recovery from the last injury and the skull was exposed. There were no signs of skull fracture or brain hemorrhage in any injury paradigm. Therefore, the injuries are characterized as mild.

\section{Periorbital and plantar tactile sensitivity}

For periorbital testing, mice were tested as described by [9]. Briefly, each mouse was acclimated to its own polycoated paper cup (Choice 4 oz. paper cups; $6.5 \mathrm{~cm}$ top diameter, 4.5 $\mathrm{cm}$ bottom diameter, $72.5 \mathrm{~cm}$ length) for $20 \mathrm{~min}$ each day for 5 to 10 days, until habituated. During each acclimation period, a von Frey filament was repeatedly approached to the periorbital area without applying pressure, in order to decrease their withdrawal reflex. Mice were considered habituated once the tip of the filament could reach the head (without any pressure) without the mouse reacting to it.

For plantar testing, mice were habituated to an acrylic chamber (dimensions 114 x $80 \mathrm{~cm}$ ) placed over a grid support (Bioseb, France), for $2 \mathrm{~h}$ on the day before the first testing, and for 30 min immediately before testing. 
A set of eight von Frey filaments was used from $\mathrm{A}(0.008 \mathrm{~g})$ to $\mathrm{H}(1 \mathrm{~g})$ (Bioseb, France). Testing was performed according to the up and down method previously described $[11 ; 16]$. Briefly, filaments were applied for $3 \mathrm{~s}$ at the periorbital area or $5 \mathrm{~s}$ at the plantar area. The $\mathrm{D}(0.07 \mathrm{~g})$ filament was applied first. If the animal reacted (withdrew the head, wiped eyes or periorbital region, withdrew, shook, or licked hindpaw for plantar), then a lower filament was applied. If there was no reaction, then a higher filament was applied. A pattern was recorded. This method was used until 5 applications after a first change in the pattern were assessed. The last filament applied and the final pattern were used to calculate the $50 \%$ threshold following an established equation $[11 ; 16]$. Since this technique does not yield continuous thresholds and data cannot be analyzed using parametric statistics, the $50 \%$ thresholds $(\mathrm{g})$ were log-transformed before being analyzed in order to obtain normally distributed data.

\section{Experimental design}

In order to reduce the number of animals used in this study, the same cohorts of mice were tested for periorbital and plantar hypersensitivity after respective injuries (multifactorial injury in Fig. $1 \mathrm{~A}$ and $1 \mathrm{~B}$, and closed head impact injury in Fig. 2A and $2 \mathrm{~B})$. However, because we wanted to limit the number of time mice were injected with treatments within the same week. different cohorts of mice were tested for periorbital and plantar hypersensitivity after subthreshold triggers in Fig. 3, 5B and 5C (periorbital) and 4, 5D and 5E (plantar). In Fig.4B, one of the cohorts tested on D21 generated aberrant results and exhibited agitated behavior all through assay. For this reason, the testing was repeated on D22, when their behavior appeared normal again. The results obtained on D22 were used for the present results, and the aberrant data of D21 were discarded.

For each experiment, mice were brought to the behavioral room for acclimation for one hour prior to handling/testing. Baseline $50 \%$ thresholds were recorded for each animal before TBI. 
Animals were then separated into experimental groups using a block randomization protocol per cage (all 4 animals within a same cage were allocated to the same injury group in case they develop anxiety, and in order to not stress sham animals). Animals in sham groups received anesthetics on 3 consecutive days in order to provide the most robust negative control. All subsequent time-points are expressed as days after the last sham or injury exposure. When treatments were administered, animals were placed back into their home cages immediately after drug administration and before the beginning of testing. Mice were tested 30 min after CGRP and $1 \mathrm{~h}$ after SNP administration.

\section{Statistical analysis}

A power analysis was performed for sample size estimation using ClinCalc.com. The effect size of this study was estimated at $50 \%$ decrease for both tactile hypersensitivity and light aversion, based on data from previous similar studies. With an alpha of 0.05 and power at 0.80 , the projected sample size needed with this effect size was approximately 14 per group for tactile hypersensitivity and 15 for light aversion. Data are reported as mean \pm SEM. Data were analyzed using GraphPad Prism 8.4 software (RRID: SCR_002798). Significance was set at $p<0.05$. No sex-specific differences were observed in this study, and the effect size was powered for analysis of males and females pooled together.

All statistics are reported in Table 1. For Fig. 1 and 2, data are plotted as a function of time (line graphs), and a two-way repeated measure ANOVA was performed (factors time and injury). For all graphs, the interaction between the two factors was significant, therefore a Tukey multiplecomparison test was performed to compare the effect of each injury at each time point. For Fig. 3B and 4B, no statistics were performed because not all injury groups received all treatments. Instead, at the different time points, statistics were assessed and presented on the scatter plots 
in Fig. 3C, 3D, 4C, 4D, 5B, 5C, 5E, 5F. For the scatter plots, since a two-way ANOVA was not possible, unpaired t-tests were used to assess the difference between 2 injury/treatment groups.

Exclusions were applied to the datasets for the following reasons: fight wounds that would have affected pain thresholds $(n=3)$ or development of dermatitis that would have affected pain threshold $(n=1)$. All data from those animals was excluded from the study. Additionally, over the 58 animals receiving the multifactorial TBI (134 injuries performed overall), 5 died on injury day (4 females, 1 male). Those animals were alive at the end of injuries but never recovered from anesthesia. There was no animal loss during the closed head impact procedure.

\section{Results}

\section{Multifactorial brain injury induces persistent tactile hypersensitivity}

The murine multifactorial brain injury model incorporates concussion and acceleration/deceleration upon exposure to an overpressure air wave, resulting in neurodegeneration and neurobehavioral deficits reminiscent of multifactorial TBI in people [17; $51 ; 57 ; 58]$. Exposure of mice to this injury (Fig. 1A) decreased the $50 \%$ thresholds (log transformed to obtain normal distribution) in the cephalic region (periorbital, on the midline just above the eyes) starting 7 days after injury and lasting for at least 9 weeks (D63, Fig. 1B). All three groups, single multifactorial injury (1MF), 3 multifactorial injuries within the same day (3MF1d), and 1 multifactorial injury every day for 3 consecutive days (3MF3d), significantly decreased thresholds compared to the sham injury group. The most severe effect was observed in 3MF3d mice (Fig. 1B).

We also evaluated tactile sensitivity in the plantar area of the paw to assess for central sensitization, which is associated with development of chronic pain. Similar to what was 
observed in the cephalic area, all groups of multifactorial TBI showed significantly decreased plantar thresholds compared to the sham injury group, from 3 weeks (D35) after injuries and for at least 7 weeks (D49, Fig. 1C). Once again, the most robust phenotype was observed in the 3MF3d group, with the decrease in thresholds reaching significance more rapidly (1 week (D7) after injury) and lasting longer (at least 9 weeks (D63)) (Fig. 1C). There was no difference observed between males and females in periorbital or plantar thresholds before or after injury in any of the groups (data not shown).

A

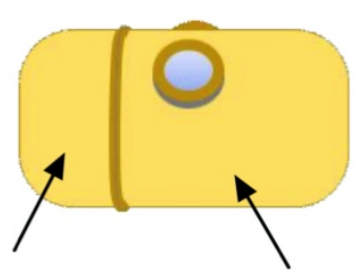

pressurized chamber sealed by mylar membrane

chamber with anesthetized mouse

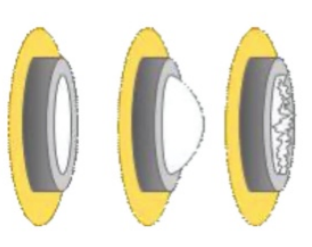

pressure increases until membrane ruptures

B

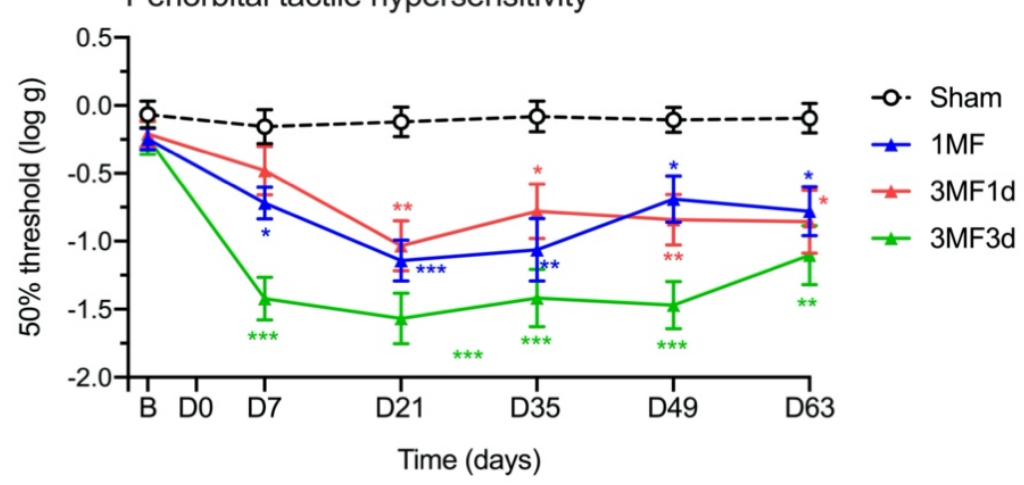

C Plantar tactile hypersensitivity

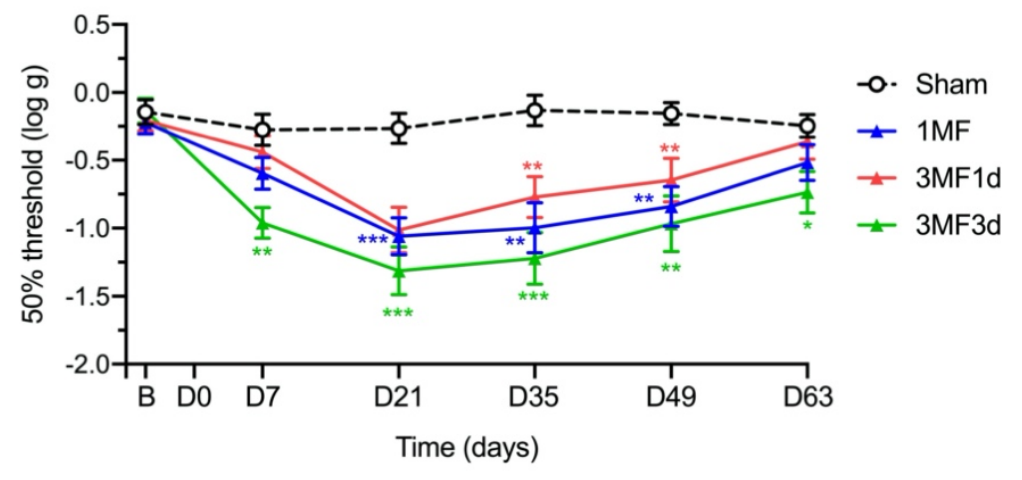


Figure 1. Multifactorial TBI induces persistent tactile hypersensitivity.

A. Schematic of the overpressure chamber in which multifactorial injury was induced. Anesthetized mice were placed in an enclosed chamber partitioned into two sides, sealed by a mylar membrane. Pressure was gradually increased in the portion of the chamber without the mouse until the membrane ruptured, generating an overpressure air wave reaching the animal's head at a pressure of $\sim 25$ PSI. B. Periorbital tactile hypersensitivity was assessed before injury at baseline (B), and at days $7,21,35,49$, and 63 after either a sham injury $(n=19)$, a single multifactorial (MF) injury (1MF, $n=20)$, 3 injuries within the same day (3MF1d, $n=17)$, or 3 injuries over 3 consecutive days (3MF3d, $n=14)$. C. Plantar tactile hypersensitivity on the same mice as in panel B. The mean \pm SEM 50\% thresholds are presented. Statistics are described in Table 1.

\section{Closed head impact TBI induces transient periorbital but not plantar tactile hypersensitivity}

We next assessed the same phenotypes in a closed head impact model of TBI induced by dropping a weight onto the intact skull (Fig. 2A). The same single and multiple injury schedule was used as with the multifactorial TBI model. All three groups, single closed head impact injury $(1 \mathrm{CHI}), 3$ injuries within 1 day $(3 \mathrm{CHI} 1 \mathrm{~d})$, or 1 injury a day for 3 consecutive days $(3 \mathrm{CHI} 3 \mathrm{~d})$, produced a decrease in cephalic $50 \%$ thresholds within 1 day (Fig. 2B). However, in contrast to multifactorial TBI, this effect was transient in all groups. The peak decrease was observed at 1 day after injury, and followed by slow recovery to sham levels at day 5 in $1 \mathrm{CHI}$ and $3 \mathrm{CHI} 1 \mathrm{~d}$ groups. As with multifactorial TBI, the most robust effect was observed in the multiple injuries over 3 days group, for which thresholds took longer ( 1 to 2 weeks) to return to normal (sham) levels (Fig. 2B). However, in contrast to what was observed with multifactorial TBI, no form of closed head impact induced a change in plantar thresholds (Fig. 2C). No differences were observed between males and females in this model. 
A

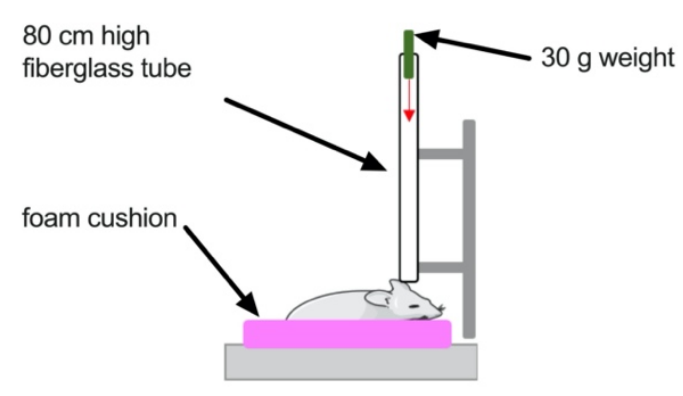

B

Periorbital tactile hypersensitivity

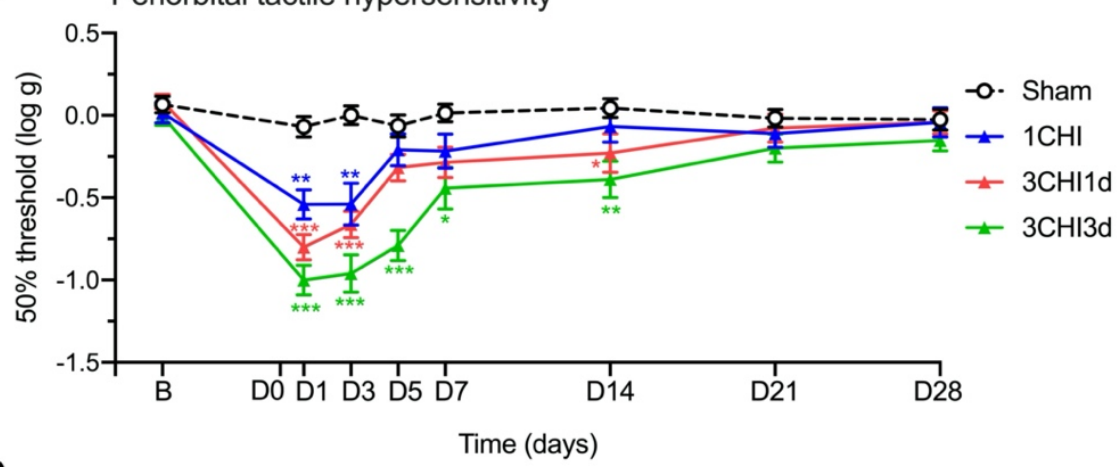

C

Plantar tactile hypersensitivity

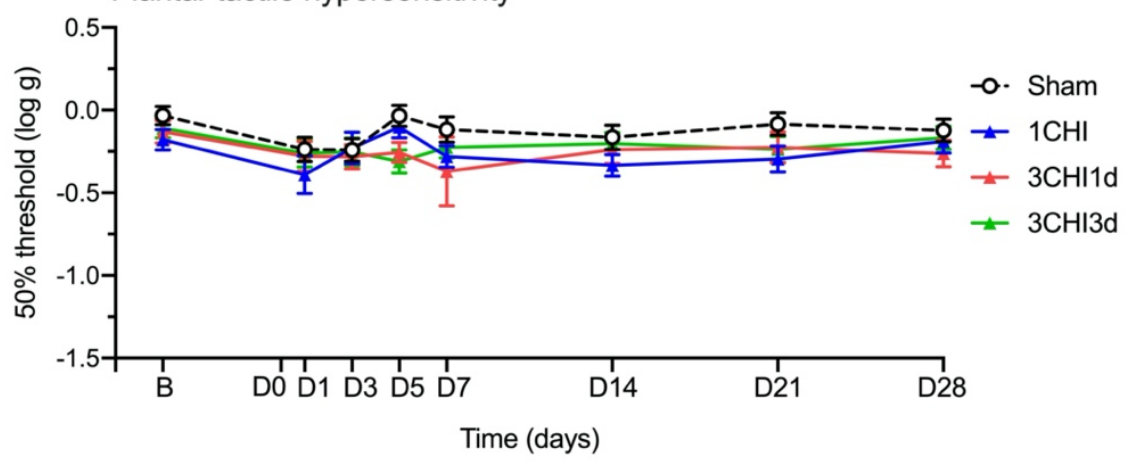

Figure 2: Closed head impact TBI induces transient periorbital tactile hypersensitivity but not plantar tactile hypersensitivity.

A. Schematic of the weight-drop apparatus in which the closed head impact injury was induced. Anesthetized mice were placed under a fiberglass tube (inner diameter $13 \mathrm{~mm}$ ), placed vertically over the mouse head. A $30 \mathrm{~g}$ metal weight was then dropped from the top of the tube $(80 \mathrm{~cm})$ to strike the head at the temporal right side between the corner of the eye and the ear. A foam cushion was placed underneath the animal to protect it from contact with the surface beneath the head trauma device and to prevent any rotational damage of the head. $\mathbf{B}$.

Periorbital tactile hypersensitivity was assessed at baseline (B) before injury, at days 1, 3, 5, 7, 14,21 , and 28 after either a sham injury $(n=16-18)$, a single closed head impact injury (1CHI, $\mathrm{n}=14-16)$, 3 injuries within the same day $(3 \mathrm{CHI} 1 \mathrm{~d}, \mathrm{n}=16-17)$, or 3 injuries over 3 consecutive days $(3 \mathrm{CHI} 3 \mathrm{~d}, \mathrm{n}=18)$. C. Plantar tactile hypersensitivity on the same mice as in panel $\mathrm{B}$. The mean \pm SEM $50 \%$ threshold are presented. Statistics are described in Table 1. 
Closed head impact sensitizes mice to non-noxious CGRP in the cephalic area

Considering that the closed head impact TBI model produced only transient symptoms, we decided to investigate whether these mice were sensitized to pain triggers around the time of recovery from periorbital tactile hypersensitivity. To begin, we tested a normally non-noxious dose of CGRP. CGRP is known to be involved in migraine, and peripheral administration of CGRP to mice induces migraine-like light aversion [32] and facial grimace that has been established to indicate the experience of spontaneous pain [44]. Here, we observed that the CGRP dose classically used to elicit light aversion and grimace $(0.1 \mathrm{mg} / \mathrm{kg}$ i.p. $)$ also caused periorbital tactile sensitivity in sham mice (Fig. 3B, D). By contrast, sham mice given a 10-fold lower dose (0.01 mg/kg i.p.) were unaffected (Fig. 3B, D), and thus this was defined as the nonnoxious dose.

The $3 \mathrm{CHI} 3 \mathrm{~d}$ mice were then given either vehicle or a subthreshold, non-noxious dose of CGRP as a subsequent trigger one week after injury. The $3 \mathrm{CHI} 3 \mathrm{~d}$ vehicle mice given vehicle displayed only a transient decrease in withdrawal thresholds before vehicle was administered, and thresholds were no different from baseline after each vehicle administration (Fig. 3B, C). However, the $3 \mathrm{CHI} 3 \mathrm{~d}$ mice treated with subthreshold CGRP one week after injury displayed a robust and significant decrease in thresholds, compared to both the sham group receiving the same dose, and the $3 \mathrm{CHI} 3 \mathrm{~d}$ group receiving vehicle (Fig. 3B, D). This sensitization persisted until at least day 91 (Fig. 3D). 
A

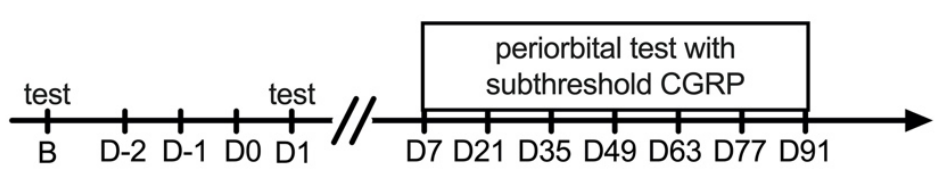

B

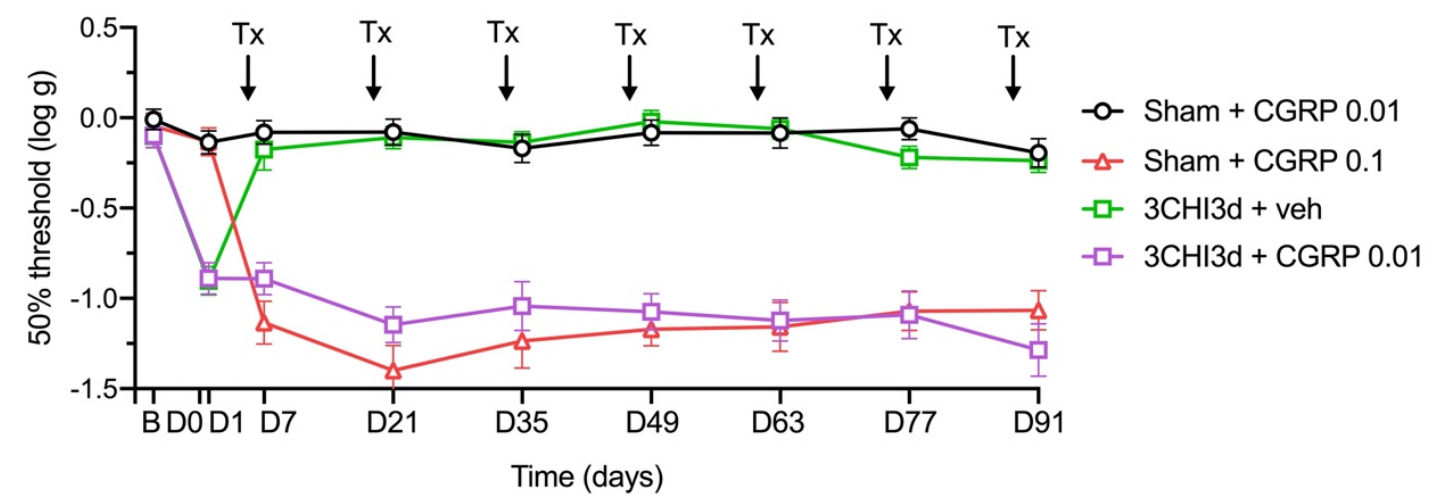

C

D1: before treatment

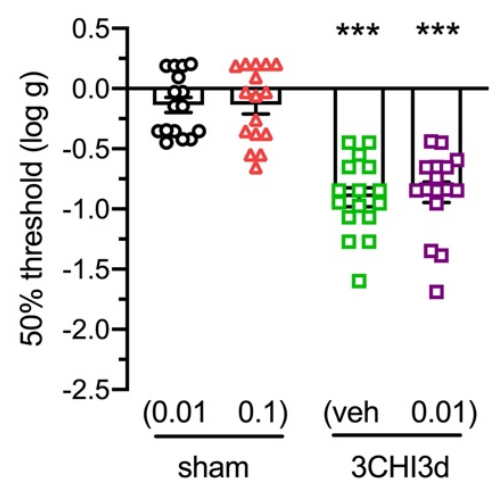

D7: after CGRP treatment

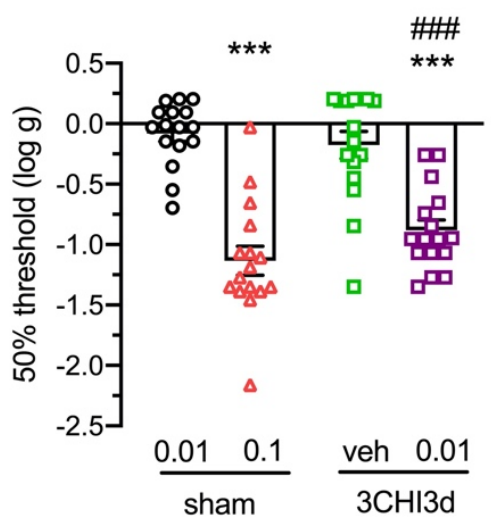

Figure 3: Closed head impact TBI sensitizes mice to non-noxious CGRP in the cephalic area.

A. Schematics of the experimental procedure. B. Periorbital tactile hypersensitivity was assessed before sham or injuries $(B)$, one day after the last sham or closed head impact injury (3CHI3d model) without any treatment (D1), and then $30 \mathrm{~min}$ after administration of vehicle, non-noxious dose of CGRP (0.01 mg/kg, i.p.), or normal dose of CGRP $(0.1 \mathrm{mg} / \mathrm{kg}$, i.p.) at days 7, 21, 35, 49, 63, 77, and 91 after the last sham/injury. C. Scatter plot representation of the individual thresholds for mice at D1 of the experiment presented in B. At D1, mice are 1 day post sham or injuries, and did not receive any treatment. D. Scatter plot representation of the individual thresholds for mice at D7 of the experiment presented in B. At D7, mice are 7 days post sham or injuries, and were tested 30 min after administration of treatments. The mean \pm SEM $50 \%$ threshold are presented in all graphs. $\mathrm{N}=15-16$ per group. Statistics are described in Table 1. 
Closed head impact sensitizes mice to non-noxious CGRP in the extracephalic area

We next tested whether the same non-noxious dose of CGRP could also decrease tactile thresholds on the paw after multiple closed head impact injuries, as it did on the head (Fig. 4A details the experimental procedure). As with periorbital sensitivity, i.p. injection of CGRP at 0.1 $\mathrm{mg} / \mathrm{kg}$ caused plantar tactile sensitivity in sham mice (Fig. 4B, D). In contrast, sham mice given a 10 -fold lower dose $(0.01 \mathrm{mg} / \mathrm{kg}$ i.p.) were unaffected (Fig. 4B, D), so this dose was considered non-noxious for extracephalic testing just as it was for periorbital testing.

As seen with the periorbital area, $3 \mathrm{CHI} 3 \mathrm{~d}$ mice that received this non-noxious dose of CGRP showed a significant decrease in $50 \%$ thresholds compared to vehicle and sham mice receiving the same CGRP dose (Fig. 4B). However, the effect was somewhat less robust than seen with the periorbital region. Specifically, it was not apparent one week after injury (Fig. 4B, C) and was only detected 3 weeks after the last injury (Fig. 4B, D). This effect persisted until at least day 91. 
A

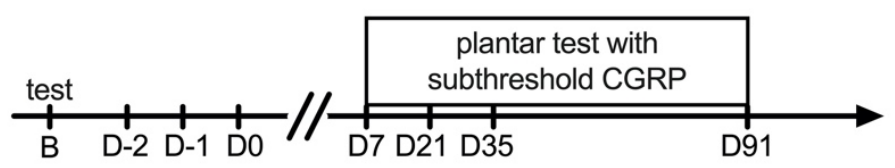

B

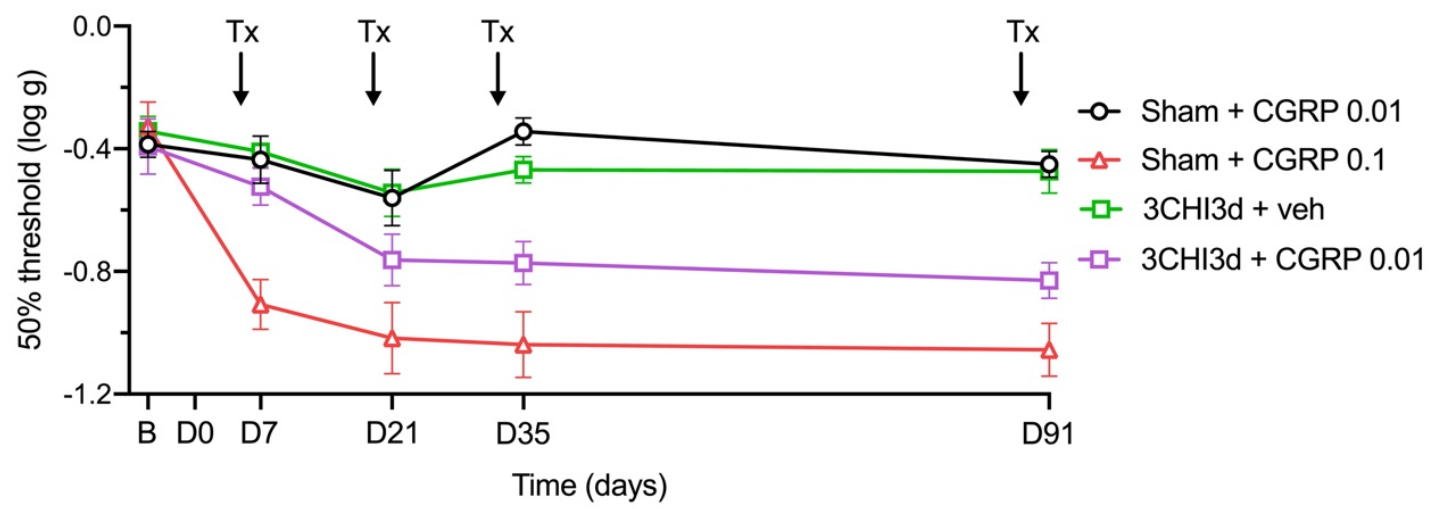

C

D7: after CGRP treatment

D

D35: after CGRP treatment
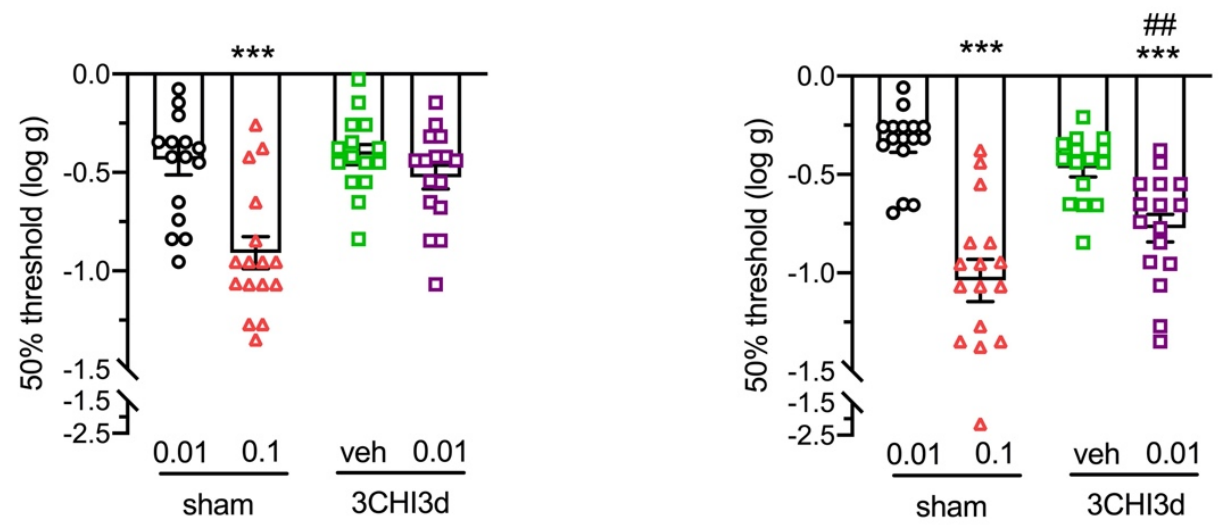

Figure 4: Closed head impact TBI sensitizes mice to non-noxious CGRP in the extracephalic area.

A. Schematic of the experimental procedure. B. Plantar tactile hypersensitivity was assessed before sham or injuries (B), one day after the last sham or closed head impact injury (3CHI3d model) without any treatment (D1), and then $30 \mathrm{~min}$ after administration of vehicle, non-noxious dose of CGRP (0.01 mg/kg, i.p.), or normal dose of CGRP $(0.1 \mathrm{mg} / \mathrm{kg}$, i.p.) at days $7,21,35$, and 91 after the last sham/injury. C. Scatter plot representation of the individual thresholds for mice at D7 of the experiment presented in B. At D7, mice are 7 day post sham or injuries, and were tested 30 min after administration of treatments. D. Scatter plot representation of the individual thresholds for mice at D35 of the experiment presented in B. At D35, mice are 35 days post sham or injuries, and were tested $30 \mathrm{~min}$ after administration of treatments. The mean \pm SEM $50 \%$ threshold are presented in all graphs. $\mathrm{N}=15-16$ per group. Statistics are described in Table 1. 
Closed head impact sensitizes mice to non-noxious sodium nitroprusside in both the cephalic and extracephalic areas

We next assessed the effect of a non-noxious dose of another migraine trigger, the nitric oxide donor sodium nitroprusside (SNP) [19] (Fig. 5A). Like CGRP, nitric oxide donors can be used pre-clinically to induce migraine-like phenotypes in mice and rats [42]. To compare with CGRP, we used the same mice used for the subthreshold experiments. Thus, the first step was to determine whether previously administered subthreshold CGRP caused a permanent sensitization of $3 \mathrm{CHI} 3 \mathrm{~d}$ mice. We re-assessed the cephalic threshold without administering vehicle or CGRP (see Fig. 5A for experimental procedure) and observed that thresholds for all groups at day 112 were back to baseline (Fig. 5B). This indicates that the evoked pain induced by subthreshold CGRP is not permanent.

As with CGRP, we observed that SNP (2.5 mg/kg i.p.) induced tactile hypersensitivity in sham mice (Fig. 5C). By contrast, mice given a 10-fold lower dose of SNP (0.25 mg/kg i.p.) were unaffected (Fig. 5C). This dose was therefore considered to be non-noxious in this assay. While the non-noxious dose did not induce any threshold change in sham animals, it did significantly decrease thresholds of $3 \mathrm{CHI} 3 \mathrm{~d}$ mice at 119 days post-injury (Fig. 5C). This decrease was significant compared to both sham mice given $0.25 \mathrm{mg} / \mathrm{kg}$ SNP and $3 \mathrm{CHI} 3 \mathrm{~d}$ mice given vehicle.

These experiments were then repeated for the plantar cohorts (see Fig. 5D for experimental procedure). Ninety-eight days after the last injury, mice were tested without treatment and the plantar thresholds were observed to be back to baseline (Fig. 5E). Thus, as with the periorbital region, trigger-induced plantar tactile hypersensitivity was not permanent. As with periorbital sensitivity, at day 102 after injury, $3 \mathrm{CHI} 3 \mathrm{~d}$ mice also showed plantar sensitization to the nonnoxious dose of SNP (Fig. 5F). 
A

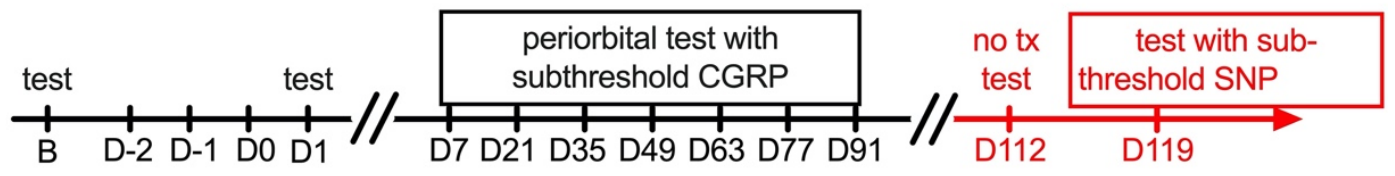

B

$$
\text { D112: no treatment }
$$

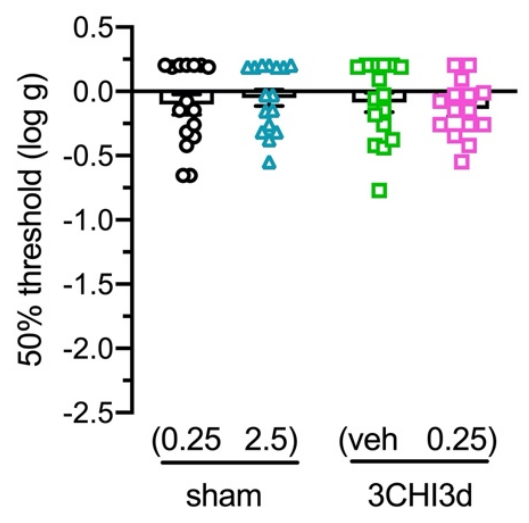

C

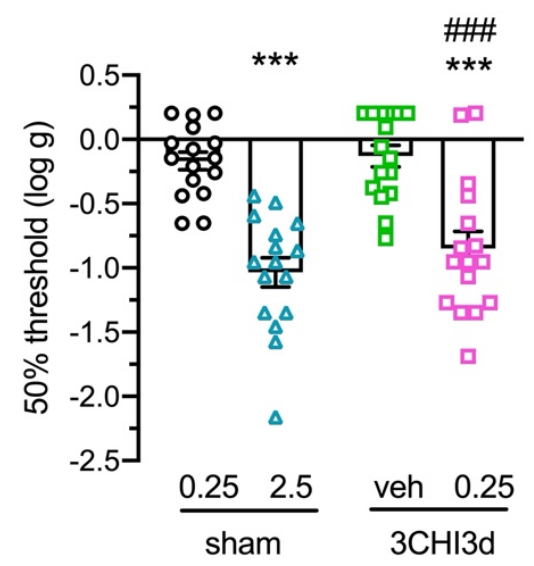

D

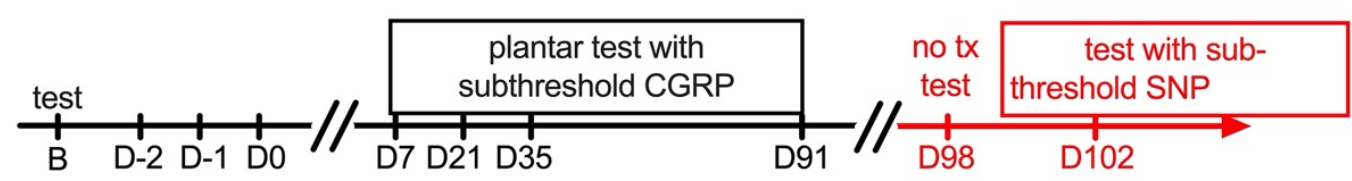

E

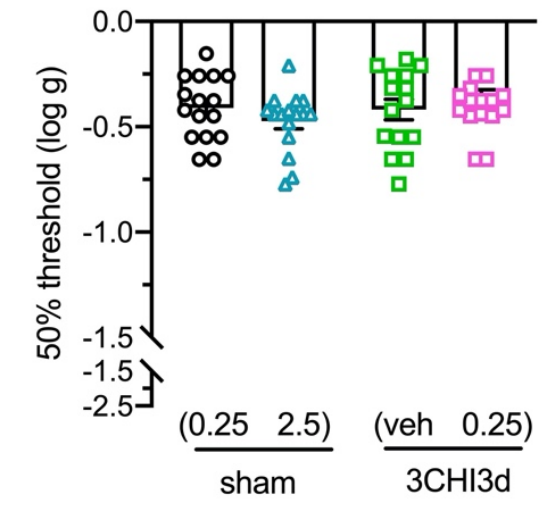

F D102: after SNP treatment

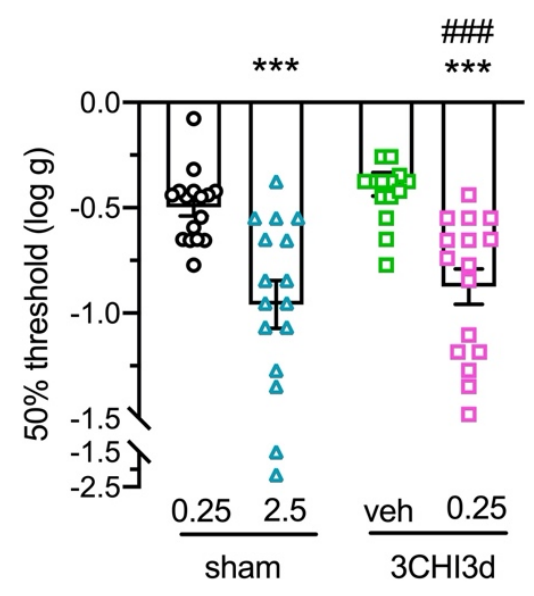

Figure 5: Closed head impact TBI sensitizes mice to non-noxious SNP in cephalic and extracephalic areas.

A. Schematic of the experimental procedure for B and C. This experiment uses the same animals as in Fig. 3 at later time-points (highlighted in red). Groups were composed of the same animals, only the treatments were changed. B. Scatter plot representation of the individual thresholds for mice at D112 of the experiment presented in Fig. 3B. At D112, mice are 112 days 
post sham or injuries, and were tested without any treatment. C. Scatter plot representation of the individual thresholds for mice at D119 of the experiment presented in Fig. 3B. At D119, mice are 119 days post sham or injuries, and were tested 60 min after administration of either vehicle, non-noxious dose of SNP (0.25 mg/kg, i.p.), or normal dose of SNP (2.5 mg/kg, i.p.). D. Schematic of the experimental procedure for $\mathrm{E}$ and $\mathrm{F}$. This experiment uses the same animals as in Fig. 4 at later time-points (highlighted in red). Groups were composed of the same animals, only the treatments were changed. E. Scatter plot representation of the individual thresholds for mice at D98 of the experiment presented in Fig. 4B. At D98, mice are 98 days post sham or injuries, and were tested without any treatment. F. Scatter plot representation of the individual thresholds for mice at D119 of the experiment presented in Fig. 4B. At D102, mice are 102 days post sham or injuries, and were tested $60 \mathrm{~min}$ after administration of either vehicle, non-noxious dose of SNP $(0.25 \mathrm{mg} / \mathrm{kg}$, i.p.), or normal dose of SNP (2.5 mg/kg, i.p.). The mean \pm SEM $50 \%$ threshold are presented in all graphs. $\mathrm{N}=15-16$ per group. Statistics are described in Table 1.

\section{Discussion}

To our knowledge, this is the first direct comparison of chronic nociceptive behaviors related to PTH induced by 2 different models of repetitive TBI. Here, we report that multifactorial TBI and closed head impact TBI induce unique patterns of tactile hypersensitivity. In multifactorial TBI, tactile hypersensitivity develops early in both cephalic and extracephalic areas and persists for at least 9 weeks. By contrast, only cephalic tactile hypersensitivity develops in closed head impact TBI, and this is transient, lasting between 1 and 7 days after injury. After that point, mice display prolonged tactile hypersensitivity in response to normally sub-threshold doses of migraine triggers.

\section{Choice of TBI models}

An increasing number of animal models for TBI are being developed, each with its own unique strengths and weaknesses [56]. The field has historically applied different models considered uniquely appropriate for different studies. Here, we assessed tactile hypersensitivity over time after TBI, a common symptom present in more than half of mild TBI patients that can be attributed to PTH and/or generalized pain [3; 39; 41]. The occurrence of this symptom seems to be independent of the etiology of the injury, although to our knowledge this has not been rigorously investigated. We chose two translatable non-penetrating models with mechanisms 
close to human TBI injury biomechanics that produce mixed diffuse-focal injuries from a focal impact moving the brain in the skull [48]. Although there are no criteria in animal models to characterize an injury as mild, moderate or severe, the lack of visible damage (no skull fracture or brain hemorrhage) and the prompt recovery of animals seem to indicate that the sustained injuries were relatively mild [15]. Moreover, there were no deaths in the closed head impact group. However, 4 females and 1 male did not recover from anesthesia after multifactorial injury, while all sham injury animals survived, indicating that multifactorial TBI, possibly in combination with anesthetics, may be somewhat more severe. A contribution from anesthetics is suggested by a report of lower mortality after TBI in awake compared to anesthetized animals [50]. The higher ratio of female mice dying from multifactorial injury might be attributed to sexspecific factors, as multiple studies show that while men are more likely to sustain a TBI, women are at greater risk for poor outcomes [45]. Furthermore, a recent finding in rats reported sexual dimorphism, with females displaying a prolonged state of cephalic hyperalgesia [8]. Aside from mortality, we did not detect any sex-specific outcomes in any of our models of TBI, although the studies were not powered to specifically address this question.

\section{Long-term vs transient hypersensitivity induced by TBI}

We found that multifactorial brain injury induced persistent periorbital and plantar tactile hypersensitivity in mice. This result is consistent with a previous study showing persistent (8 weeks) whisker-pad tactile hypersensitivity after a single direct bullet-less gun-induced TBI in rats estimated at >70 PSI [49]. Interestingly, in a subsequent study, this phenotype was not produced when the TBI was performed in awake animals [50], despite the known protective effect of anesthetics [30]. It was hypothesized that the anesthetized model may have a more robust blast wave dissipation due to better placement of the apparatus on the animal, which would result in a more severe injury [50]. The same team also showed that a single injury induced persistent spontaneous pain, as characterized by the rat grimace scale [49; 50$]$. 
By comparison, we observed that closed head impact in mice induced transient periorbital tactile hypersensitivity, consistent with previous studies in both mice and rats $[7 ; 8 ; 37 ; 40]$. However, we did not observe any plantar hypersensitivity. Plantar hypersensitivity is controversial, with some studies reporting sensitivity in rats $[7 ; 8]$ and others reporting only a transient plantar hypersensitivity in C57BL6/J mice [37; 40]. As our experiments were conducted in CD1 mice, the difference of mouse strains may be a possible explanation for the discrepancy.

\section{Single vs. repeated TBI}

The present findings show in both models that the more injuries received, the more robust the PTH-like phenotype. In patients, it is increasingly reported that subsequent brain injuries are associated with more severe pathology and symptomatology, and it is widely presumed that morbidity after repeated TBI will be proportional to the number of brain injuries sustained [5; 12; 34]. In a review, Hall and colleagues point out that only one study using repeated weight-drop injury models showed a scaled response with increasing number of TBI [5; 47]. All other studies, including ours, show a cumulative but not a strictly additive effect.

With some injuries going unreported [35], athletes may sustain multiple injuries within the same day, or have long inter-injury intervals. For this reason, we chose to compare different injury paradigms. The preclinical literature is inconsistent on the topic, but the majority of studies seem to indicate that inter-injury intervals of less than 5 days seem to worsen the symptoms [36; 52], while injuries sustained months apart seem to either ameliorate [22; 36] or not change [36] the outcome. Interestingly, a pattern of 3 injuries received over 3 consecutive days was more deleterious in our models than 3 injuries within the same day. However, a caveat of our study lies with the likely neuroprotective effect of anesthetic. Animals injured 3 times within the same day had to be sequentially re-anesthetized three times, which could have affected the depth of anesthesia and minimized damage. As with all preclinical studies, the relevance of these results 
to the human condition in which patients are not anesthetized before TBI must be interpreted with caution. Alternatively, there could be effects of combining a new primary injury with a developing secondary injury. At this time, it is difficult to choose the optimal interval between injuries in an animal model.

Mild closed head impact sensitizes to sub-threshold migraine triggers after symptoms resolution

Patients who recover from TBI-induced symptoms within the first few weeks/months after injury often develop chronic neurologic changes with sensitization to stressors [13]. Hence, we tested whether TBI sensitized the mice to subthreshold doses of CGRP. Given that persistent hypersensitivity was observed in the multifactorial TBI model, we used the closed head impact mice to address this question. We chose CGRP as our initial stressor because clinical similarities between TBI-induced PTH and primary headaches suggests that PTH could be triggered through the same signaling pathways [3]. The neuropeptide CGRP is also recognized as a critical player in the pathophysiology of migraine [54]. In mice, at a dose of $0.1 \mathrm{mg} / \mathrm{kg}$ i.p., CGRP induces spontaneous pain [44] and light-aversion [32]. In this study, we have extended these symptoms to include both periorbital and plantar tactile hypersensitivity. While a 10-fold lower dose is normally unable to induce those symptoms in mice, we show that it does provoke both periorbital and plantar tactile hypersensitivity in mice after repeated injuries. Remarkably, this phenotype lasted for more than 100 days after injury. This sensitivity to CGRP after TBI is reminiscent of the increased sensitivity to CGRP of migraine patients [2;20;21;25].

Similarly, closed head impact mice can also re-develop tactile periorbital and plantar sensitivity after administration of subthreshold SNP (10-fold lower dose than normal), another migraine trigger [19]. This is consistent with previous findings of tactile hypersensitivity after administration of a low dose of nitroglycerin to rats and mice $[7 ; 8 ; 37]$. Both SNP and nitroglycerin are nitric oxide donors that induce migraine-like symptoms in part by recruiting 
CGRP [3]. An additional piece of evidence highlighting the similarities between migraine and PTH in animal models is that after closed head impact, mice become sensitized and develop periorbital hypersensitivity when exposed to bright light [40]. Those results raise the possibility that infusion of CGRP or SNP in TBI patients might trigger migraine-like headache like they do in migraineurs. This also further supports the likely possibility that TBI patients could respond to CGRP targeting drugs, such as CGRP and receptor blocking antibodies, or small molecule antagonists (gepants), to prevent or treat headache. A few preclinical studies support this idea, although closed head impact was the only model tested for this hypothesis $[7 ; 8 ; 37 ; 40]$. Indeed, the first clinical trial is ongoing now to evaluate efficacy and tolerability of the CGRP receptor antibody erenumab for treatment of patients suffering from persistent PTH (NCT03974360).

\section{Conclusion}

Multiple animal models are needed to investigate the PTH-like symptoms experienced by patients suffering from the wide variety of TBls. Here, we have characterized a multifactorial model that mimics persistent hypersensitivity and central sensitization, and a closed head impact model that mimics persistent sensitization to subsequent migraine triggers. The ability to model sustained and transient symptoms is reminiscent of the variability in persistence and manifestation of headache and pain in TBI patients [4; 5; 27; 41]. Furthermore, our results with these models offer support for a causative role of CGRP in $\mathrm{PTH}$, underscoring the potential utility of CGRP-targeting drugs for treatment of TBI-induced PTH and pain symptoms.

\section{Acknowledgments}

The authors would like to thank Dr. Dan Levy and Dr. Dara Bree for teaching the closed head impact model to A-S.W. and L.P.S. 
This work was supported by the Department of Defense grants W81XWH-16-1-0211 and W81XWH-16-1-0071 (A.F.R., A.A.P), Department of Veterans Affairs Merit award 1I0RX002101 (A.F.R., A.A.P.), and Department of Veterans Affairs Career Development Award IK2 RX002010 012020 (L.P.S, A.F.R). This work was also funded by a Pilot project awarded under The Center for the Prevention and Treatment of Visual Loss (award C9251-C) from the Department of Veterans Affairs Rehabilitation R\&D Services (A-S.W.). A-S.W. was also supported for this work by the International Headache Academy research award from the American Headache Society. A.A.P. was supported for this work by the Brockman Foundation, Elizabeth Ring Mather \& William Gwinn Mather Fund, S. Livingston Samuel Mather Trust, G.R. Lincoln Family Foundation, and the Louis Stokes VA Medical Center resources and facilities. The contents do not represent the views of VA or the United States Government. 
Table 1: Statistical analyses.

\begin{tabular}{|c|c|c|}
\hline Figure \# & Analysis & Statistics \\
\hline Figure 1B & $\begin{array}{l}\begin{array}{l}\text { Two-way repeated measure ANOVA } \\
\text { Interaction factor } \\
\text { Injury factor } \\
\text { Time factor }\end{array} \\
\begin{array}{l}\text { Tukey's multiple comparisons between injuries } \\
{ }^{*} p<0.05,{ }^{* *} p<0.01,{ }^{* * *} p<0.001 \text { compared to } \\
\text { vehicle. }\end{array}\end{array}$ & $\begin{array}{l}F_{(15,330)}=2.936, p=0.0002 \\
F_{(3,66)}=17.76, p<0.0001 \\
F_{(4.4,290.5)}=16.40, p<0.0001\end{array}$ \\
\hline Figure 1C & $\begin{array}{l}\begin{array}{l}\text { Two-way repeated measure ANOVA } \\
\text { Interaction factor } \\
\text { Injury factor } \\
\text { Time factor }\end{array} \\
\begin{array}{l}\text { Tukey's multiple comparisons between injuries } \\
{ }^{*} p<0.05,{ }^{* *} p<0.01,{ }^{* * *} p<0.001 \text { compared to } \\
\text { vehicle. }\end{array}\end{array}$ & $\begin{array}{l}F_{(15,330)}=2.370, p=0.003 \\
F_{(3,66)}=16.14, p<0.0001 \\
F_{(4.4,293.5)}=17.33, p<0.0001\end{array}$ \\
\hline Figure 2B & $\begin{array}{l}\begin{array}{l}\text { Two-way repeated measure ANOVA } \\
\text { Interaction factor } \\
\text { Injury factor } \\
\text { Time factor }\end{array} \\
\begin{array}{l}\text { Tukey's multiple comparisons between injuries } \\
{ }^{*} p<0.05,{ }^{* *} p<0.01,{ }^{* * *} p<0.001 \text { compared to } \\
\text { vehicle. }\end{array}\end{array}$ & $\begin{array}{l}F_{(21,441)}=5.778, p<0.0001 \\
F_{(3,63)}=15.51, p<0.0001 \\
F_{(5.9,372)}=43.38, p<0.0001\end{array}$ \\
\hline Figure 2C & $\begin{array}{l}\text { Two-way repeated measure ANOVA } \\
\qquad \begin{array}{r}\text { Interaction factor } \\
\text { Injury factor } \\
\text { Time factor }\end{array}\end{array}$ & $\begin{array}{l}F_{(21,434)}=0.6589, p=0.8731 \\
F_{(3,62)}=1.883, p=0.1417 \\
F_{(5.1,313.4)}=2.177, p=0.0558\end{array}$ \\
\hline Figure 3C & $\begin{array}{l}\text { Unpaired t-tests } \\
\text { - Sham } 0.01 \text { vs. Sham } 0.1 \\
\text { - Sham } 0.01 \text { vs. TBI } 0.01 \\
\text { - TBI veh vs. TBI } 0.01 \\
\text { - Sham } 0.1 \text { vs. TBI veh } \\
\end{array}$ & $\begin{array}{l}p=0.9760 \\
p<0.0001 \\
p=0.7249 \\
p<0.0001\end{array}$ \\
\hline Figure 3D & $\begin{array}{l}\text { Unpaired t-tests } \\
\text { - Sham } 0.01 \text { vs. Sham } 0.1 \\
\text { - Sham } 0.01 \text { vs. TBI } 0.01 \\
\text { - TBI veh vs. TBI } 0.01\end{array}$ & $\begin{array}{l}p<0.0001 \\
p<0.0001 \\
p<0.0001\end{array}$ \\
\hline Figure 4C & $\begin{array}{l}\text { Unpaired t-tests } \\
\text { - Sham } 0.01 \text { vs. Sham } 0.1 \\
\text { - Sham } 0.01 \text { vs. TBI } 0.01 \\
\text { - TBI veh vs. TBI } 0.01\end{array}$ & $\begin{array}{l}p=0.0002 \\
p=0.3728 \\
p=0.1645\end{array}$ \\
\hline Figure 4D & $\begin{array}{l}\text { Unpaired t-tests } \\
\text { - Sham } 0.01 \text { vs. Sham } 0.1 \\
\text { - Sham } 0.01 \text { vs. TBI } 0.01 \\
\text { - TBI veh vs. TBI } 0.01\end{array}$ & $\begin{array}{l}p<0.0001 \\
p<0.0001 \\
p=0.0011\end{array}$ \\
\hline Figure 5B & $\begin{array}{l}\text { Unpaired t-tests } \\
\text { - Sham } 0.25 \text { vs. Sham } 2.5 \\
\text { - Sham } 0.25 \text { vs. TBI } 0.25 \\
\text { - TBI veh vs. TBI } 0.25\end{array}$ & $\begin{array}{l}p=0.6149 \\
p=0.7372 \\
p=0.6174\end{array}$ \\
\hline Figure 5C & $\begin{array}{l}\text { Unpaired t-tests } \\
\text { - Sham } 0.25 \text { vs. Sham } 2.5\end{array}$ & $p<0.0001$ \\
\hline
\end{tabular}


bioRxiv preprint doi: https://doi.org/10.1101/2020.06.01.127944; this version posted June 2, 2020. The copyright holder for this preprint (which was not certified by peer review) is the author/funder, who has granted bioRxiv a license to display the preprint in perpetuity. It is made available under aCC-BY-NC-ND 4.0 International license.

\begin{tabular}{|l|l|l|}
\hline & - Sham 0.25 vs. TBI 0.25 & $p<0.0001$ \\
& - TBI veh vs. TBI 0.25 & $p<0.0001$ \\
\hline Figure 5E & Unpaired t-tests & \\
& - Sham 0.25 vs. Sham 2.5 & $p=0.2339$ \\
& - Sham 0.25 vs. TBI 0.25 & $p=0.5376$ \\
& - TBI veh vs. TBI 0.25 & $p=0.5066$ \\
\hline Figure 5F & Unpaired t-tests & \\
& - Sham 0.25 vs. Sham 2.5 & $p=0.0006$ \\
& - Sham 0.25 vs. TBI 0.25 & $p=0.0004$ \\
& - TBI veh vs. TBI 0.25 & $p<0.0001$ \\
\hline
\end{tabular}




\section{References}

[1] Amyot F, Kenney K, Spessert E, Moore C, Haber M, Silverman E, Gandjbakhche A, Diaz-

Arrastia R. Assessment of cerebrovascular dysfunction after traumatic brain injury with fMRI and fNIRS. Neuroimage Clin 2020;25:102086.

[2] Asghar MS, Hansen AE, Amin FM, van der Geest RJ, Koning P, Larsson HB, Olesen J,

Ashina M. Evidence for a vascular factor in migraine. Ann Neurol 2011;69(4):635-645.

[3] Ashina H, Porreca F, Anderson T, Amin FM, Ashina M, Schytz HW, Dodick DW. Posttraumatic headache: epidemiology and pathophysiological insights. Nat Rev Neurol 2019;15(10):607-617.

[4] Baandrup L, Jensen R. Chronic post-traumatic headache--a clinical analysis in relation to the International Headache Classification 2nd Edition. Cephalalgia 2005;25(2):132-138.

[5] Bolton-Hall AN, Hubbard WB, Saatman KE. Experimental Designs for Repeated Mild Traumatic Brain Injury: Challenges and Considerations. J Neurotrauma 2019;36(8):1203-1221.

[6] Brasure M, Lamberty GJ, Sayer NA, Nelson NW, MacDonald R, Ouellette J, Tacklind J, Grove M, Rutks IR, Butler ME, Kane RL, Wilt TJ. Multidisciplinary Postacute Rehabilitation for Moderate to Severe Traumatic Brain Injury in Adults. Rockville (MD), 2012.

[7] Bree D, Levy D. Development of CGRP-dependent pain and headache related behaviours in a rat model of concussion: Implications for mechanisms of post-traumatic headache. Cephalalgia 2018;38(2):246-258.

[8] Bree D, Mackenzie K, Stratton J, Levy D. Enhanced post-traumatic headache-like behaviors and diminished contribution of peripheral CGRP in female rats following a mild closed head injury. Cephalalgia 2020:333102420907597. 
[9] Burgos-Vega CC, Quigley LD, Trevisan Dos Santos G, Yan F, Asiedu M, Jacobs B, Motina M, Safdar N, Yousuf H, Avona A, Price TJ, Dussor G. Non-invasive dural stimulation in mice: A novel preclinical model of migraine. Cephalalgia 2019;39(1):123-134.

[10] Cassidy JD, Carroll LJ, Peloso PM, Borg J, von Holst H, Holm L, Kraus J, Coronado VG, Injury WHOCCTFoMTB. Incidence, risk factors and prevention of mild traumatic brain injury: results of the WHO Collaborating Centre Task Force on Mild Traumatic Brain Injury. J Rehabil Med 2004(43 Suppl):28-60.

[11] Chaplan SR, Bach FW, Pogrel JW, Chung JM, Yaksh TL. Quantitative assessment of tactile allodynia in the rat paw. J Neurosci Methods 1994;53(1):55-63.

[12] Covassin T, Elbin R, Kontos A, Larson E. Investigating baseline neurocognitive performance between male and female athletes with a history of multiple concussion. $\mathrm{J}$ Neurol Neurosurg Psychiatry 2010;81(6):597-601.

[13] Daneshvar DH, Riley DO, Nowinski CJ, McKee AC, Stern RA, Cantu RC. Long-term consequences: effects on normal development profile after concussion. Phys Med Rehabil Clin N Am 2011;22(4):683-700, ix.

[14] Dewan MC, Rattani A, Gupta S, Baticulon RE, Hung YC, Punchak M, Agrawal A, Adeleye AO, Shrime MG, Rubiano AM, Rosenfeld JV, Park KB. Estimating the global incidence of traumatic brain injury. J Neurosurg 2018:1-18.

[15] Dewitt DS, Perez-Polo R, Hulsebosch CE, Dash PK, Robertson CS. Challenges in the development of rodent models of mild traumatic brain injury. J Neurotrauma 2013;30(9):688-701.

[16] Dixon WJ. The Up-and-Down method for small samples. Journal of the American Statistical Association 1965;60(312):967-978.

[17] Dutca LM, Stasheff SF, Hedberg-Buenz A, Rudd DS, Batra N, Blodi FR, Yorek MS, Yin T, Shankar M, Herlein JA, Naidoo J, Morlock L, Williams N, Kardon RH, Anderson MG, Pieper AA, Harper MM. Early detection of subclinical visual damage after blast-mediated 
TBI enables prevention of chronic visual deficit by treatment with P7C3-S243. Invest Ophthalmol Vis Sci 2014;55(12):8330-8341.

[18] Faul M, Coronado V. Epidemiology of traumatic brain injury. Handb Clin Neurol 2015;127:313.

[19] Guo S, Ashina M, Olesen J, Birk S. The effect of sodium nitroprusside on cerebral hemodynamics and headache in healthy subjects. Cephalalgia 2013;33(5):301-307.

[20] Guo S, Vollesen AL, Olesen J, Ashina M. Premonitory and nonheadache symptoms induced by CGRP and PACAP38 in patients with migraine. Pain 2016;157(12):27732781.

[21] Hansen JM, Hauge AW, Olesen J, Ashina M. Calcitonin gene-related peptide triggers migraine-like attacks in patients with migraine with aura. Cephalalgia 2010;30(10):11791186.

[22] Harper MM, Woll AW, Evans LP, Delcau M, Akurathi A, Hedberg-Buenz A, Soukup DA, Boehme N, Hefti MM, Dutca LM, Anderson MG, Bassuk AG. Blast Preconditioning Protects Retinal Ganglion Cells and Reveals Targets for Prevention of Neurodegeneration Following Blast-Mediated Traumatic Brian Injury. Invest Ophthalmol Vis Sci 2019;60(13):4159-4170.

[23] Headache Classification Committee of the International Headache S. The International Classification of Headache Disorders, 3rd edition (beta version). Cephalalgia 2013;33(9):629-808.

[24] Kim S, Han SC, Gallan AJ, Hayes JP. Neurometabolic indicators of mitochondrial dysfunction in repetitive mild traumatic brain injury. Concussion 2017;2(3):CNC48.

[25] Lassen LH, Haderslev PA, Jacobsen VB, Iversen HK, Sperling B, Olesen J. CGRP may play a causative role in migraine. Cephalalgia 2002;22(1):54-61.

[26] Levy D, Edut S, Baraz-Goldstein R, Rubovitch V, Defrin R, Bree D, Gariepy H, Zhao J, Pick CG. Responses of dural mast cells in concussive and blast models of mild traumatic 
brain injury in mice: Potential implications for post-traumatic headache. Cephalalgia 2016;36(10):915-923.

[27] Levy D, Gruener H, Riabinin M, Feingold Y, Schreiber S, Pick CG, Defrin R. Different clinical phenotypes of persistent post-traumatic headache exhibit distinct sensory profiles. Cephalalgia 2019:333102419896368.

[28] Lew HL, Lin PH, Fuh JL, Wang SJ, Clark DJ, Walker WC. Characteristics and treatment of headache after traumatic brain injury: a focused review. Am J Phys Med Rehabil 2006;85(7):619-627.

[29] LoPinto C, Young WB, Ashkenazi A. Comparison of dynamic (brush) and static (pressure) mechanical allodynia in migraine. Cephalalgia 2006;26(7):852-856.

[30] Luh C, Gierth K, Timaru-Kast R, Engelhard K, Werner C, Thal SC. Influence of a brief episode of anesthesia during the induction of experimental brain trauma on secondary brain damage and inflammation. PLoS One 2011;6(5):e19948.

[31] Ma VY, Chan L, Carruthers KJ. Incidence, prevalence, costs, and impact on disability of common conditions requiring rehabilitation in the United States: stroke, spinal cord injury, traumatic brain injury, multiple sclerosis, osteoarthritis, rheumatoid arthritis, limb loss, and back pain. Arch Phys Med Rehabil 2014;95(5):986-995 e981.

[32] Mason BN, Kaiser EA, Kuburas A, Loomis MM, Latham JA, Garcia-Martinez LF, Russo AF. Induction of Migraine-Like Photophobic Behavior in Mice by Both Peripheral and Central CGRP Mechanisms. J Neurosci 2017;37(1):204-216.

[33] Mathew NT, Kailasam J, Seifert T. Clinical recognition of allodynia in migraine. Neurology 2004;63(5):848-852.

[34] McAllister T, McCrea M. Long-Term Cognitive and Neuropsychiatric Consequences of Repetitive Concussion and Head-Impact Exposure. J Athl Train 2017;52(3):309-317. [35] McCrea M, Hammeke T, Olsen G, Leo P, Guskiewicz K. Unreported concussion in high school football players: implications for prevention. Clin J Sport Med 2004;14(1):13-17. 
[36] Meehan WP, 3rd, Zhang J, Mannix R, Whalen MJ. Increasing recovery time between injuries improves cognitive outcome after repetitive mild concussive brain injuries in mice. Neurosurgery 2012;71(4):885-891.

[37] Moye LS, Novack ML, Tipton AF, Krishnan H, Pandey SC, Pradhan AA. The development of a mouse model of mTBI-induced post-traumatic migraine, and identification of the delta opioid receptor as a novel therapeutic target. Cephalalgia 2019;39(1):77-90.

[38] Mullally WJ. Concussion. Am J Med 2017;130(8):885-892.

[39] Nampiaparampil DE. Prevalence of chronic pain after traumatic brain injury: a systematic review. JAMA 2008;300(6):711-719.

[40] Navratilova E, Rau J, Oyarzo J, Tien J, Mackenzie K, Stratton J, Remeniuk B, Schwedt T, Anderson T, Dodick D, Porreca F. CGRP-dependent and independent mechanisms of acute and persistent post-traumatic headache following mild traumatic brain injury in mice. Cephalalgia 2019;39(14):1762-1775.

[41] Ofek H, Defrin R. The characteristics of chronic central pain after traumatic brain injury. Pain 2007;131(3):330-340.

[42] Pradhan AA, Smith ML, McGuire B, Tarash I, Evans CJ, Charles A. Characterization of a novel model of chronic migraine. Pain 2014;155(2):269-274.

[43] Prevention CfDCa. Report to congress on traumatic brain injury in the United States: epidemiology and rehabilitation.: Atlanta (GA): National Center for Injury Prevention and Control: Division of Unintentional Injury Prevention, 2015.

[44] Rea BJ, Wattiez AS, Waite JS, Castonguay WC, Schmidt CM, Fairbanks AM, Robertson BR, Brown CJ, Mason BN, Moldovan-Loomis MC, Garcia-Martinez LF, Poolman P, Ledolter J, Kardon RH, Sowers LP, Russo AF. Peripherally administered calcitonin gene-related peptide induces spontaneous pain in mice: implications for migraine. Pain 2018;159(11):2306-2317. 
[45] Rubin TG, Lipton ML. Sex Differences in Animal Models of Traumatic Brain Injury. J Exp Neurosci 2019;13:1179069519844020.

[46] Sabirzhanov B, Stoica BA, Zhao Z, Loane DJ, Wu J, Dorsey SG, Faden Al. miR-711 upregulation induces neuronal cell death after traumatic brain injury. Cell Death Differ 2016;23(4):654-668.

[47] Shultz SR, Bao F, Omana V, Chiu C, Brown A, Cain DP. Repeated mild lateral fluid percussion brain injury in the rat causes cumulative long-term behavioral impairments, neuroinflammation, and cortical loss in an animal model of repeated concussion. J Neurotrauma 2012;29(2):281-294.

[48] Siebold L, Obenaus A, Goyal R. Criteria to define mild, moderate, and severe traumatic brain injury in the mouse controlled cortical impact model. Exp Neurol 2018;310:48-57.

[49] Studlack PE, Keledjian K, Farooq T, Akintola T, Gerzanich V, Simard JM, Keller A. Blastinduced brain injury in rats leads to transient vestibulomotor deficits and persistent orofacial pain. Brain Inj 2018;32(13-14):1866-1878.

[50] Uddin O, Studlack PE, Parihar S, Keledjian K, Cruz A, Farooq T, Shin N, Gerzanich V, Simard JM, Keller A. Chronic pain after blast-induced traumatic brain injury in awake rats. Neurobiol Pain 2019;6:100030.

[51] Vazquez-Rosa E, Watson MR, Sahn JJ, Hodges TR, Schroeder RE, Cintron-Perez CJ, Shin MK, Yin TC, Emery JL, Martin SF, Liebl DJ, Pieper AA. Neuroprotective Efficacy of a Sigma 2 Receptor/TMEM97 Modulator (DKR-1677) after Traumatic Brain Injury. ACS Chem Neurosci 2019;10(3):1595-1602.

[52] Vest V, Bernardo-Colon A, Watkins D, Kim B, Rex TS. Rapid Repeat Exposure to Subthreshold Trauma Causes Synergistic Axonal Damage and Functional Deficits in the Visual Pathway in a Mouse Model. J Neurotrauma 2019;36(10):1646-1654. 
[53] Wang KK, Yang Z, Zhu T, Shi Y, Rubenstein R, Tyndall JA, Manley GT. An update on diagnostic and prognostic biomarkers for traumatic brain injury. Expert Rev Mol Diagn 2018;18(2):165-180.

[54] Wattiez AS, Sowers LP, Russo AF. Calcitonin gene-related peptide (CGRP): role in migraine pathophysiology and therapeutic targeting. Expert Opin Ther Targets 2020;24(2):91-100.

[55] Witcher KG, Eiferman DS, Godbout JP. Priming the inflammatory pump of the CNS after traumatic brain injury. Trends Neurosci 2015;38(10):609-620.

[56] Xiong Y, Mahmood A, Chopp M. Animal models of traumatic brain injury. Nat Rev Neurosci 2013;14(2):128-142.

[57] Yin TC, Britt JK, De Jesus-Cortes H, Lu Y, Genova RM, Khan MZ, Voorhees JR, Shao J, Katzman AC, Huntington PJ, Wassink C, McDaniel L, Newell EA, Dutca LM, Naidoo J, Cui H, Bassuk AG, Harper MM, McKnight SL, Ready JM, Pieper AA. P7C3 neuroprotective chemicals block axonal degeneration and preserve function after traumatic brain injury. Cell Rep 2014;8(6):1731-1740.

[58] Yin TC, Voorhees JR, Genova RM, Davis KC, Madison AM, Britt JK, Cintron-Perez CJ, McDaniel L, Harper MM, Pieper AA. Acute Axonal Degeneration Drives Development of Cognitive, Motor, and Visual Deficits after Blast-Mediated Traumatic Brain Injury in Mice. eNeuro 2016;3(5). 